\title{
Presencia del clero en la Revolución Cuzqueña de 1814: ideas y actitudes de Francisco Carrascón
}

\author{
Miguel Molina MARTÍNEZ \\ Universidad de Granada \\ mimolina@ugr.es
}

Recepción: 8 de noviembre de 2009 / Revisión: 5 de abril de 2010 Aceptación: 20 de abril de 2010 / Publicación: diciembre de 2010

\begin{abstract}
RESUMEN
Este artículo analiza la participación del sacerdote Francisco Carrascón en la revolución de Cuzco en 1814. Se presta especial atención a sus escritos que animaban a la independencia y a la creación de una patria peruana con el fin de profundizar en su pensamiento y conocer sus ideales revolucionarios. Finalmente se estudia el proceso militar al que fue sometido y su sentencia.
\end{abstract}

Palabras clave: clérigos patriotas, Francisco Carrascón, Perú, propaganda antiespañola, Revolución del Cuzco en 1814, siglo XIX.

\section{Presence of the Clergy in the Cuzco Revolution of 1814: Ideas and attitudes of Francisco Carrascón}

\begin{abstract}
This article analyzes priest Francisco Carrascon's participation in the revolution of Cuzco in 1814. Particular attention is paid to his writings that encouraged independence and the creation of a Peruvian homeland, in order to allow a profound study of his thought and discern his revolutionary ideas. Finally we study the military trial to which he was subjected and his subsequent sentence.
\end{abstract}

Keywords: Cleric Patriots, Francisco Carrascón, Perú, Anti-Spanish Propaganda, Cuzco Revolution of 1814, 19th Century.

SUMARIO: 1 . El personaje y el contexto. 2. La proclama. 3. Los sermones. 4. El proceso y la sentencia. 5. Referencias bibliográficas.

\section{EL PERSONAJE Y EL CONTEXTO}

La posición de la iglesia americana ante los movimientos insurgentes ha sido objeto de estudio desde fecha muy temprana. Son bien conocidas las actitudes a favor del bando realista que adoptó un nutrido grupo de la alta jerarquía eclesiástica, siendo bastante más reducidas las de los obispos que, por el contrario, abrazaron la causa independentista ${ }^{1}$. Menos conocida, en cambio, es la postura del clero americano, particularmente el secular, al frente de sus parroquias en el momento decisivo del estallido de la rebelión. En el caso del Perú no faltan los estudios que se han ocupa-

\footnotetext{
1 Para un análisis más general en el que se aborda esta cuestión véase VARGAS UGARTE, 1945.
} 
do del tema y cuyas conclusiones oscilan entre quienes sostienen que la implicación con el bando patriota fue mayoritaria y quienes matizan sustancialmente tal afirmación $^{2}$. En cualquier caso, estas investigaciones han puesto de manifiesto que el papel de los religiosos fue importante y, en algunos casos, decisivo en el desarrollo de aquellos acontecimientos. Unos, comandando tropas rebeldes que se enfrentaron a los ejércitos realistas; otros, proporcionando el discurso ideológico que justificaba la insurrección. Estos últimos ofrecieron a la población argumentos que daban sentido a la lucha a través de su oratoria y de textos donde política y religión se confundían en un mismo fin.

El interés histórico que posee toda esa literatura -proclamas o sermones- en la que, bajo un ropaje religioso y bíblico, el clero propagó un discurso político independentista fundamenta este trabajo y persigue profundizar en el significado de tales escritos. El análisis se centra en la figura del racionero de la catedral de Cuzco, Francisco Carrascón y Sola, un sacerdote cuya participación en la revolución cuzqueña de 1814 fue notable, aunque desde el punto de vista historiográfico haya quedado relegado a un plano secundario.

Sin embargo, no es ésta la primera vez que el personaje ha sido objeto de atención por parte de los investigadores. Aparicio Vega le dedicó algunas páginas, reparó en el carácter revolucionario de sus escritos y publicó algunos de ellos en la Colección Documental de la Independencia de Perú3. Marie-Danielle Demelas se sirvió de ellos para plantear una visión de la revolución cuzqueña de 1814 bajo un prisma mesiánico y providencialista ${ }^{4}$. Luis Miguel Glave abordó también su figura y lo calificó como "un exuberante visionario", prestando especial interés al cuadro que mandó pintar el clérigo y cuya iconografía guardaba estrecha relación con el de sus textos revolucionarios 5 . Finalmente nosotros mismos estudiamos una etapa anterior de su biografía, caracterizada ésta por las tensas relaciones que mantuvo con el obispo de Cuzco, Bartolomé de las Heras, y el inicio de su actitud crítica hacia la administración hispana ${ }^{6}$.

Algunas pinceladas biográficas de Francisco Carrascón y Sola permiten conocer la evolución del personaje y la altura de miras de su trayectoria. Nacido en Zaragoza a principios de marzo de 1759, cursó estudios mayores en la Universidad de esa ciudad, ampliando después su formación en los conventos dominicos de Pamplona y Orihuela. En 1784 fue ordenado sacerdote y pasó a ocupar el puesto de teniente de cura del Real Sitio y Hospital de San Fernando. Seis años después fue nombrado

2 Un acercamiento al tema en VARetTo, 1922; Aparicio Vega, 1974; García Jordán, 1982; SALA I VILA, 1994; KAIBLER, 2001.

3 Aparicio Vega, 1974, parte II, cap. IV; ColeCCión, 1974, tomo III, vol. 7.

4 Demelas, 1995, 1997 y 2003.

${ }^{5}$ Este trabajo inédito se incluye en la primera parte de su tesis doctoral y agradezco al Dr. Glave la información y observaciones brindadas al respecto. La segunda parte de la tesis en GLAVE, 2004. El boceto de dicho cuadro se encuentra en el Expediente de la causa militar seguida contra Carrascón, acompañando a la declaración del pintor, Pascual Olivares. Archivo General de Indias (en adelante AGI), Cuzco, 71, f. 80. También en AGI, Mapas y Planos, Estampas, 48. Lo publicó Aparicio VegA, 1974, pp. 150-151, con una descripción del mismo.

6 Molina Martínez, 2008. 
capellán del segundo regimiento de infantería del Príncipe, destacado en la guarnición de Alicante. Entre 1790-1791 desempeñó su ministerio en la plaza y presidio de Melilla, desde donde fue ascendido a la capellanía del regimiento de caballería de Alcántara en calidad de cura párroco castrense. Como tal participó en las campañas del Rosellón y el Ampurdán desde 1793 hasta 1795. Abandonó el campo de batalla a causa de una enfermedad, continuando su labor eclesiástica en el Puerto de Santa María ${ }^{7}$. Intercedió ante el arzobispo de Sevilla para que se le otorgase alguna pensión por los servicios realizados en las campañas de Francia o, en su defecto, la obtención de alguna prebenda en América. De este modo, fue propuesto para las plazas de arcediano de la catedral de La Habana y de tesorero de la de Santiago, pero sin éxito alguno. Finalmente fue propuesto para la plaza de racionero de la catedral de Cuzco, vacante por la muerte de su titular, Eugenio Hermosa, mediante real cédula de 5 de junio de 1798. Tomó posesión de ella el 28 de enero de $1800^{8}$.

La presencia de Carrascón en Cuzco convulsionó la vida de la diócesis por su actitud díscola, sus denuncias y los pleitos de los que no escaparon las máximas autoridades. Muchos de sus comportamientos llamaron la atención por no ser "decorosos a su carácter y prebenda", entre ellos, promover pleitos entre los vecinos y actuar de abogado, o formar parte de una compañía de comedias tras asociarse con dos actores. Dotado de un fuerte carácter, mantuvo un tenaz enfrentamiento con el obispo de las Heras, que había sido su protector, así como con el presidente y ciertos oidores de la Audiencia cuzqueña que censuraron su comportamiento. Carrascón, en su afán reformista, tuvo la osadía de denunciar las prácticas corruptas que observó en aquel obispado y señaló como último responsable de aquella situación a su titular, Bartolomé de las Heras. Aún más, implicó a la Real Audiencia de la que criticaba su connivencia con el obispo y la actitud parcial ante sus quejas. Fue una voz crítica que no calló ante situaciones irregulares y vicios que a fuerza de repetirse habían sido aceptados como admisibles ${ }^{9}$. Coincidía en su crítica con el maestrescuela de la catedral de Cuzco, José Fernando Baeza, quien también había hecho llegar al rey los excesos del obispo y los de su mayordomo Ignacio Puerta ${ }^{10}$.

Se esforzó en presentarse como un cristiano celoso de su trabajo y un fiel vasallo que actuaba por el bien de su rey, y plasmó en innumerables escritos dirigidos a la Corona las prácticas corruptas y abusivas que observaba en el obispado. No tuvo

${ }^{7}$ Hoja de servicios de Francisco Carrascón. Madrid, 14-VIII-1797. AGI, Cuzco, 70.

8 Acta de la toma de posesión certificada por Tadeo Gárate, secretario del cabildo de la catedral. Cuzco, 28-I-1800. AGI, Cuzco, 73. Tadeo Gárate, que llegó a ser intendente de Puno, fue un político ligado al poder español, diputado a Cortes y firmante del Manifiesto de los Persas; de nuevo en América, siguió defendiendo la causa realista y firmó la sentencia de muerte del pasquinista Bernardino Tapia. Véase Berruezo, 1986; GlaVe, 2005a, pp. 137-141.

9 Representación de Francisco Carrascón al Consejo de Indias. Cuzco, 8-VIII-1801. AGI, Cuzco, 70.

10 Representación de José Fernando Baeza al rey. Cuzco, 10-III-1804. AGI, Cuzco, 70. Baeza, en su deseo de ser "útil a la Religión, al Rey y al Estado", fue autor también de una Propuesta sobre la extinción de la lengua quechua, medios para su logro en breves años sin necesidad de enseñar a leer a los indios y sobre el aumentar la gruesa de diezmos en este obispado a otro tanto o algo más de lo que hoy importa en el bienio, con sólo no rematar la coca y sí ponerla en administración. Cuzco, 28-VI1798. AGI, Cuzco, 70. 
reparo en afirmar que gran parte de las dignidades eclesiásticas de Cuzco eran desempeñadas por ilegítimos y con profusión de concubinatos con la total permisividad del obispo o que éste era promotor e inductor de hechos reprobables y censurables ${ }^{11}$. Cuando a finales de 1804 el Consejo de Indias desoyó sus denuncias, salvaguardando la dignidad y autoridad de De las Heras y de la Real Audiencia, Carrascón lejos de amedrentarse mantuvo su actitud beligerante durante los años siguientes. No le faltaban motivos de queja. Por las mismas fechas había visto también cómo las autoridades silenciaban su proyecto de crear un virreinato con sede en Puno que incluía, además, un ambicioso programa de comunicaciones para enlazar el Alto Perú con las costas atlántica y pacífica por medio de una vasta red fluvial ${ }^{12}$. La unánime oposición que suscitó semejante propuesta en Cuzco, Lima y Madrid nunca la entendió y todavía en 1814 la seguía defendiendo como útil para el desarrollo de aquella región andina y lamentando su rechazo ${ }^{13}$.

Convencido de que era objeto de la arbitrariedad de los funcionarios reales y de que sufría una persecución que en modo alguno merecía, Carrascón acabó considerándose una víctima del sistema. Quizá esta circunstancia pudo hacer crecer en él un malestar que, poco después, se desbordó manifestándose en una dura crítica al orden colonial, la que le llevó a implicarse en la insurrección junto a los hermanos Angulo. Sin embargo, no sería ésta la única razón que explicase la participación de Carrascón en la revolución cuzqueña de 1814. Su afán de revancha no habría llegado demasiado lejos si hubiera carecido de una sólida formación intelectual; Carrascón fue un hombre culto, de amplias lecturas, y al tanto de las nuevas corrientes ideológicas. Sus escritos, en este sentido, ofrecen bastante luz acerca de su pensamiento y descubren a un hombre entusiasta con el nuevo orden constitucional anunciado en Cádiz y, frustrado éste, partidario del establecimiento de una nación peruana independiente.

Como señaló acertadamente Aparicio Vega, el clero patriota se sirvió de los sermones, proclamas y ceremonias religiosas para encender el espíritu revolucionario y así llegar al mayor número de habitantes. En los púlpitos, en los atrios o en la calle, la retórica de los curas desempeñó un papel clave en la propagación del conflicto,

La fulminante oratoria del clero patriota - escribe Aparicio Vega-, no sólo destrozaba el orgullo realista y laceraba la injusticia y hacía saltar pues a borbotones en la lacra de la dominación, sino que convertía en decididos soldados a los eternos explotados por el imperialismo hispano ${ }^{14}$.

Francisco Carrascón formó parte de ese grupo de clérigos que puso al servicio de la revolución no sólo sus grandes dotes de declamación, sino también su formación

${ }^{11}$ La evolución de este conflicto y sus causas se abordan en Molina MartínEZ, 2008.

12 Este ambicioso proyecto, presentado al Consejo de Indias en 1802, planteaba también la creación de un nuevo obispado segregado del de Cuzco y la erección de una capitanía general. AGI, Lima, 773. El proyecto iba acompañado de una cartografía bastante detallada de la región que puede consultarse en la Mapoteca Virtual del Ministerio de Relaciones Exteriores de Perú, VPE-136, Virreinato del Perú:www.rree.gob.pe/portal/ArchivoH.nsf/GaleriaImagenes/5D7E14C1FE3C17FB05256D08007604 2?OpenDocument.

13 Representación de Francisco Carrascón al rey. Cuzco, 21-IV-1814. AGI, Cuzco, 70.

14 Aparicio Vega, 1974, p. 111. 
religiosa, jurídica e intelectual. Fue autor de una proclama y dos sermones cuyo contenido revolucionario le supuso a la postre su arresto y condena. La importancia de dichos textos está fuera de toda duda y de ahí el interés que tienen para el investigador a la hora de abordar el conflicto desde otros parámetros. La proclama, que vio la luz el 16 de agosto de 1814, es decir pocos días después de haber dado comienzo la insurrección de los Angulo, es una pieza bien elaborada y de extensión considerable (véase infra). El primero de los sermones guarda relación con el triunfo de las tropas insurgentes en Arequipa y con el apresamiento de las autoridades realistas. Este sermón formó parte de la celebración en Cuzco de aquella victoria que incluía la bendición de las banderas; de ahí que esta pieza oratoria fuera conocida bajo tal nombre. El segundo sermón ha llegado a través de un borrador y en él se pretende exaltar la figura de los llamados mártires de la noche del 5 de noviembre de 1813. Fue pronunciado el día de San Andrés a propósito del aniversario de la fundación del Hospital del mismo nombre en Cuzco, según se explica en su texto (véase infra).

\section{LA PROCLAMA}

Comienza esta pieza ${ }^{15}$ con la invocación "mis amados compatriotas del Bajo y Alto Perú" y se extiende a lo largo de trece puntos, cuyas ideas principales pueden resumirse en la siguiente manera:

- La insurrección forma parte de una larga secuencia de movimientos contra las injusticias que sufren los pueblos desde la Antigüedad.

- Derecho de los hombres a formar gobiernos y delimitar un territorio para su desarrollo, siempre por voluntad de la Divina Providencia.

- Crítica a los monarcas españoles por la abdicación de Bayona y denuncia de que faltaron a su juramento real, lo que justifica el movimiento insurreccional.

- Como consecuencia de lo anterior, es legítimo que el pueblo se organice en cortes generales y extraordinarias.

- Afirmación de que los territorios americanos no son colonias, ni sus habitantes conquistados, sino hombres libres.

- Los españoles americanos son iguales y gozan de los mismos derechos que los españoles peninsulares.

- Los reyes gobiernan para la felicidad del pueblo y no para su violencia y abuso.

15 Proclama de Francisco Carrascón. Cuzco. 16-VIII-1814. AGI, Cuzco, 71. Un extracto de la misma se recoge en APARICIO VEGA, 1974, pp. 128-132. Nosotros trabajamos con el documento existente en AGI, que se incluye como pieza en la causa formada contra Carrascón por las autoridades realistas. 
- La gran extensión territorial del dominio español y la diversidad geográfica y cultural es origen de enfrentamientos e injusticias entre sus partes.

- Para evitarlo, es justa la creación de una nación separada y cimentada sobre la unidad de costumbres y tradiciones.

- Llamamiento a la unidad de los habitantes del Alto y Bajo Perú frente al despotismo español.

- Creación de un nuevo imperio peruano bajo la protección de Jesucristo y los caudillos de la insurgencia.

- Proyecto de patria peruana basado en la igualdad y los méritos, sin privilegios ni distinción de razas y colores.

Como puede observarse, el soporte ideológico que animaba la proclama guarda una estrecha relación con las ideas planteadas en la Península a raíz de la invasión napoleónica: monarquía acéfala, pactismo, movimiento juntista, constitucionalismo... Nada original, si se tiene en cuenta que argumentos similares formaron parte de otras muchas proclamas americanas e incluso declaraciones de independencia de la época. Sin embargo, su texto pone de manifiesto que Carrascón conocía la literatura política de su tiempo y que supo aprovecharla para sus fines. A diferencia de lo que señala Aparicio Vega, esta proclama rebosa de argumentos políticos y jurídicos y ello la convierte en un documento que trasciende lo meramente militar ${ }^{16}$. Su extensión más larga de lo habitual se justifica precisamente por la inclusión en ella de los fundamentos ideológicos que alientan la revolución. Los argumentos que legitiman la lucha son presentados de forma sistemática y coherente. La crítica al Antiguo Régimen se entremezcla con los nuevos principios liberales; viejas doctrinas pactistas emergen para dar sentido a la insurrección y, aunque no se nombre, es reconocible el influjo de filósofos pertenecientes a la escolástica tradicional española y a otras corrientes del pensamiento europeo.

En este sentido, la abdicación de la corona española a favor de Napoleón proporcionó un primer sólido argumento para justificar la ruptura. Partiendo del hecho de que aquélla faltó al deber sagrado contraído con los españoles, Carrascón dedujo que el monarca quedó inhábil para gobernar y, por consiguiente, no pudo sino concluir que

[...] habiéndonos faltado el rey, no faltamos nosotros a la fidelidad debida de nuestro juramento en negarle una ciega obediencia que nos destruye y en separarnos de una sociedad que nos devora.

16 Para este historiador peruano la proclama "estaba destinada a dar el máximo valor a los soldados del ejército patriota para que luchen decididamente por la felicidad del pueblo [...] era como una inyección de pólvora que le armaba de valor y decisión; la proclama contenía más terminología militar que jurídica”. Aparicio Vega, 1974, p. 125. 
En efecto, la situación provocada en 1808 apuntaló la imagen de una monarquía acéfala y desencadenó un intenso debate político, canalizado primero a través de la Junta Suprema Central y consumado después en las Cortes de Cádiz. La ruptura del vínculo por parte de la monarquía permitió que los pueblos se arrogasen la representación de un poder que en la práctica ya no existía. Carrascón no fue ajeno a los cambios derivados de la nueva realidad y dejó constancia clara de ello en su proclama. Siguiendo la estela de autores como Francisco Suárez, Grocio, Hobbes o Locke consideraba que los reyes habían hecho dejación de su compromiso con el pueblo y ello legitimaba la actitud rebelde de éste. Especialmente la idea del pactum translationis suarecino sirvió a Carrascón como base jurídica de su proyecto. En su opinión, la formación de las juntas de gobierno y la convocatoria de Cortes no eran sino la consecuencia final e inevitable del cautiverio de Fernando VII y daba por sentado que, ausente el rey, el poder revertía al pueblo representado en aquéllas.

En América caló profundamente la idea de que la abdicación de Bayona les había liberado de todas sus obligaciones con la Península y que, consecuentemente, estaban legitimados para establecer nuevos gobiernos. Más aún cuando el Real Decreto de 22 de enero de 1809 había señalado que las tierras americanas no eran colonias, sino una parte integrante de la monarquía en igualdad de derechos con el resto de territorios. Tan sorprendente declaración de la Junta Central fue recibida en los dominios ultramarinos con toda su literalidad y como tal fue esgrimida por todos los líderes en sus reivindicaciones. También por Carrascón que hizo referencia a ella para dar fuerza a sus planteamientos independentistas. Con un eficaz estilo retórico encendía los ánimos de los cuzqueños en estos términos:

Compatriotas míos, si los americanos y todos los que disfrutamos este su benigno y bastísimo continente ya no somos colonias de los Europeos y menos sus conquistados, si ya somos unos hombres por naturaleza libres cuya libertad a más de ser de suyo natural nos la han declarado y publicado en tan autorizadas Cortes los propios hijos y representantes de los buenos, o malos, y únicos conquistadores de este nuestro hemisferio americano, ¿por qué dudamos de nuestra libertad?, ¿qué vínculos pueden oprimir?, ¿por qué no seremos libres por este heroico acto de nuestra emancipación en Cortes?, ¿por qué pues no recibimos con la debida gratitud de los verdaderos representantes de los conquistadores de este nuestro suelo los bienes patrios que nos franquea hasta la misma naturaleza? ¿por qué en virtud de esta declaración o donación no usamos nuestros naturales derechos de la libertad americana como aquellos otros humanos de la suya Península? ¿por qué si aquéllos formando una insurrección general en toda su Península pretenden arrojar a sus opresores franceses contra los decretos de sus dos últimos reyes Carlos y Fernando, nosotros no haremos lo mismo siendo iguales a ellos?

La convocatoria de procesos electorales, hecha por la Junta Central y luego por la Regencia, alcanzó en Cuzco un nivel de confrontación desconocido en otras regiones. Absolutistas y constitucionalistas se disputaron el poder en aquellos comicios, desembocando en la revolución del 3 de agosto de 1814 que lideró José Angulo17.

17 Véanse Fisher, 1979; GlaVe, 2001; Peralta Ruiz, 1996. 
Aunque para entonces los constitucionalistas habían ganado la batalla y controlaban el poder local, el objetivo de los sublevados trascendía al de los dos bandos rivales. En esencia, aquel movimiento pretendía

[...] rescatar una tradición política de tipo consuetudinario [...] rota por el absolutismo borbónico y por la modernización política patrocinada por los constitucionalistas ${ }^{18}$.

Se trataba de una tercera vía que se enfrentaba tanto al viejo poder virreinal como a las nuevas autoridades municipales.

Según Carrascón, la pérdida de las libertades provocada por el gobierno tiránico español, que es comparado con una "horrorosa serpiente de siete cabezas", estaba en el origen del malestar general de los habitantes de América y particularmente de los de Cuzco $^{19}$. Y se pregunta: "¿qué necesidad tenemos de alimentar a tal dragón insaciable de nuestra sangre?". En otras palabras,

Si Dios permitió, concedió o puso reyes a los pueblos para que éstos fuesen gobernados en justicia [...] fue siempre para que vivieran con ellos, viesen sus necesidades con sus propios ojos y sufriesen las intemperies de su propio y natural suelo y disfrutasen también con ellos sus producciones, mas no para que de seis mil leguas los mandasen, cuyas órdenes muchas veces se dirigiesen a los muertos y otras tan intempestivas que cuando llegasen a su cumplimiento fuesen más en desprecio de su autoridad que en el deseado beneficio o remedio que se tenía pedido.

No obstante, lo más revolucionario y provocador de su proclama fue la propuesta de un "nuevo imperio peruano", regido por los propios habitantes sobre la base de las riquezas naturales del territorio

Nosotros pues -escribe- los americanos del alto y bajo Perú y todos los que disfrutamos de la diversidad de sus climas..., nosotros que gozamos en nuestro patrio suelo la feracidad de los mejores del mundo..., nosotros que tenemos los frutos más apetecidos de las gentes; nosotros que podemos disfrutar la constitución de leyes que nuestra propia naturaleza nos dictase; nosotros que por todas partes nos hallamos rodeados

18 Peralta Ruiz, 1996, p. 101.

19 Es significativo cómo su proclama identifica cada una de esas siete cabezas con abusos, injusticias o mal gobierno de los españoles en América: "con la primera que fue la de los informes secretos de los magistrados y su ninguna residencia y castigo a sus falsedades que son los que han perdido la América; con la segunda, la de la pública y secreta venalidad de los empleos y honores a cuyo título se les permitía los mayores excesos contra estos colonos; con la tercera, la de los obispos de gabinete formados por los reales palaciegos y sin la canónica responsabilidad en los concilios; la cuarta, con el universal despotismo de los mandones en nuestras vidas y haciendas, obligándonos a ser atabaleros de sus vicios y sus tributarios; la quinta, la de un gobierno dilapidador de los más sagrados derechos de los ciudadanos con las voces de calle porque tenemos otras leyes, decretos de las que están en los códigos para nuestro gobierno; la sexta con las distancia y separación de los dos continentes de millares de leguas; y con la séptima, la de la imposibilidad para todo recurso". Repárese en el hecho de que algunas de estas afirmaciones guardan una relación directa con la propia experiencia de Carrascón, que siempre se consideró perseguido por los tribunales de justicia y por las autoridades políticas y religiosas. Su resentimiento hacia el modelo colonial es notorio. 
de montes de oro y de cerros de plata y de los demás preciosos metales del mundo, circundados de collados de todas carnes, depositarios de toda clase de alimentos, y ya dueños de nosotros mismos qué necesidad, pregunto, tenemos de ser dominados por otros que por nosotros mismos.

Un "nuevo imperio peruano" que se extendería desde la costa atlántica hasta la pacífica y regido por una junta de gobierno con capital en Cuzco. Su meta era la consecución de un proyecto político que

[...] uniéndonos de sol a sol y de mar a mar en este su natural punto nos forme una nación fuerte y respetable entre todas las del mundo y nos defienda ambas costas con su comercio marítimo y sus lanchas cañoneras; y el que esta soberana y serenísima junta declarando a Buenos Aires, Lima, Montevideo y el Cuzco en ciudades de primer orden con el decoroso título de Excelencia y Plaza de Armas con igual fuerza por sus respetos internos y externos, sea la del Cuzco, por su localidad y antigüedad, el punto del ángulo de su reunión ${ }^{20}$.

Proponía, asimismo, un modelo de nación integrador que no excluyera a nadie y por ello se esforzaba en convocar a todos los habitantes con un mensaje de unidad que se antoja más utópico que real

Venid pues -exclama- de buena voluntad españoles europeos y americanos y cuantos habitan el globo; venid indios dueños y felices en este imperio del Perú, que si venid de buena voluntad para todos habrá un fértil suelo para trabajarlo si lo queréis tener por patria [...] Vivamos todos en la igualdad, en la fe y lenidad de nuestros admirados y dignos jefes y descendientes de la ilustre familia de los Angulos y Mollinedos y no reconozcamos ya más privilegios que los propios de la justicia de nuestros méritos, en favorecer mutuamente y servir con nuestra sangre a nuestra propia y general patria peruana que nos ha vivificado y mantiene con el éter vital de estas sus ricas y abundantes producciones ${ }^{21}$.

Comparada la proclama de Carrascón con el manifiesto lanzado por José Angulo al pueblo de $\mathrm{Cuzco}^{22}$, llama la atención que aquél se exprese en un lenguaje directamente independentista y éste, en cambio, insista todavía en proclamar la fidelidad al monarca y a las Cortes:

El numeroso pueblo - escribe Angulo-, la fuerza armada y todas las corporaciones han ratificado solemnemente la Constitución política de la monarquía, la fidelidad a nuestro amado monarca el Sr. D. Fernando VII, a las Cortes soberanas, y a la serenísi-

${ }^{20}$ Algunas ideas y expresiones del texto fueron reflejadas simbólicamente en el cuadro que mandó pintar. Véase la descripción de VEGA APARICIO, 1974, pp. 148-151.

${ }^{21}$ El protagonismo indígena en la región había sufrido cambios importes a partir de la rebelión de Tupac Amaru en 1780 y las posteriores reformas borbónicas que con sus elevadas exigencias fiscales dieron origen a una nueva realidad y a nuevas alianzas interétnicas. Véase CAHILL, 1984; O'PHELAN, 1985; SAla I VILA, 1991, 1996.

22 Manifiesto al pueblo de Cuzco. Cuzco, 16-VIII-1814. Reproducido en Romero, 1977, T. I, pp. 204-208; repárese en la circunstancia de que ambos documentos están fechados el mismo día. 
ma Regencia del reino, cuyas determinaciones espero y a las cuales doy cuenta instruida con documentos de la sanidad de mis procedimientos [...] Entre tanto, espero que todos los vecinos de los pueblos y partidos de mi mando y de todos los honrados y fieles americanos se mantengan en unión, paz y tranquilidad, conserven el orden público en el mismo estado dispuesto por la Constitución y leyes de las cortes soberanas...

Cabría plantearse, como ya sucediera en otros territorios por aquellas mismas fechas, la posibilidad de afirmar que la intención de Angulo fuese disimular sus fines separatistas utilizando la fidelidad al rey y a la Constitución como una "máscara"23. Sin embargo, en ese mismo texto Angulo ofrece otras referencias sobre las verdaderas razones de la sublevación. Tal como ha estudiado Víctor Peralta, sus objetivos eran la búsqueda de una antigua libertad perdida y la restitución de la soberanía no delegable de una tradición rota desde las reformas borbónicas, precisando que Angulo justificó el tiranicidio, amparándose en leyes naturales, para restaurar el poder legítimo de la antigua comunidad local24. Desde esta perspectiva, las conexiones con la proclama de Carrascón eran evidentes, convirtiendo a ésta en un vehículo efectivo para la difusión y justificación del movimiento.

Existen en ella, sin embargo, otras ideas que no dejan de sorprender. Se trata de las constantes referencias al mundo religioso, las alusiones a la Divina Providencia, y a las citas bíblicas que salpican el texto, comprensibles en principio por la formación religiosa de su autor, pero que pueden estar relacionadas con otros planteamientos. Observación ésta también válida para los sermones donde las apelaciones a los pasajes bíblicos tienen una presencia todavía más acusada. A la vista de esta circunstancia, Marie-Danielle Demélas se preguntó sobre las razones por las que el clero insistió tanto en la dimensión religiosa de la sublevación y lanzó la interrogante de si era compatible una lucha política de tipo moderno con otra inspirada en una visión religiosa del mundo. Su respuesta fue simple. Basándose en el estudio de los sucesos de Quito, Cuzco y los Valles del Alto Perú, concluyó que aquellos conflictos eran una "guerra religiosa", una guerra de liberación anunciada por Dios ${ }^{25}$.

La tesis resulta atrevida pero algunos datos inducen a tenerla en consideración. En concreto, las primeras líneas de la proclama insisten en que los sucesos desencadenados a partir del 3 de agosto de 1814 eran voluntad de la Divina Providencia calificando la insurrección de "santa y universal". La proclama de Carrascón lleva a la conclusión de que la causa de la independencia es querida por Dios, que Cuzco es una ciudad santa y que José Angulo encarna un nuevo Moisés. Así pues, es el "omnipotente Dios" quien interviene para establecer la justicia y castigar al tiránico gobierno. Su oratoria y dotes de convicción se dirigieron a transmitir el mensaje de que con la protección divina los habitantes de América pudieron reaccionar ante el cautiverio de los reyes en Bayona, formar juntas de gobierno y convocar Cortes, declarar su

23 El tema de la máscara de Fernando VII ha sido y sigue siendo objeto de un amplio debate historiográfico. Véase GlaVE, 2005, pp. 281-288 a propósito del libro de LANDAVAZO, 2001.

24 Peralta Ruiz, pp. 123-125.

25 Demelas, 1995, p. 163. Un nuevo acercamiento al tema en Demelas, 1997. El papel de Carrascón como forjador de emblemas e imágenes para la revolución se sugiere también en DEMELAS, 2003, p. 354. 
igualdad con los peninsulares y legitimar su lucha por la libertad. Es así cómo el deán de la catedral de Cuzco preconizó un modelo de insurrección santificada, basada en un imaginario religioso de tipo mesiánico, capaz de equiparar al mismo tiempo la causa patriótica y el culto católico. Es así cómo Angulo condujo la revolución en defensa de la religión y de la patria.

\section{LOS SERMONES}

Esta integración del móvil político-revolucionario en el contexto de un imaginario religioso de carácter mesiánico tiene su mejor y más completa expresión en los textos de los sermones pronunciados en Cuzco por Carrascón: uno en la Catedral y otro en la iglesia de la Compañía ${ }^{26}$. El contenido de ambos recoge planteamientos políticos similares a los de la proclama, distinguiéndose de aquélla por el hecho de que en éstos, como se ha indicado, las referencias religiosas adquieren un protagonismo más acusado. Los sermones eran, desde siglos atrás, un vehículo eficaz para la transmisión de mensajes de muy diferente naturaleza y gozaban de una alta consideración entre la población ${ }^{27}$. La oratoria sagrada, con su fuerte carga simbólica, alusiones bíblicas, teológicas y hasta mitológicas, resultó ser en manos de Carrascón un instrumento vigoroso para sus fines propagandísticos al servicio de la revolución y de su líder José Angulo. Su influencia no debe menospreciarse en el contexto de una sociedad habituada a recibir mensajes revolucionarios a través de otras vías tan seductivas como periódicos o pasquines ${ }^{28}$. La familiaridad de Carrascón con el género era evidente como se deduce de la existencia en su biblioteca de un tomo de los sermones del que fuera considerado una autoridad en la materia, el presbítero peruano Juan de Espinosa Medrano, más conocido como el Lunarejo ${ }^{29}$. Según la tradición, sus sermones en la catedral de Cuzco constituían un verdadero acontecimiento seguido con interés y expectación por todos los feligreses. Debió ser consciente Carrascón del impacto de aquellos artificios de oratoria, por lo que aplicó su esfuerzo a componer otros semejantes dirigidos, esta vez, a la exaltación revolucionaria.

El sermón de la bendición de las banderas, pronunciado el 8 de septiembre de 1814 en la catedral con la precisa asistencia del obispo José Pérez de Armendáriz responde a estos criterios. Se trata de una pieza densa, bien construida y repleta de símbolos que tratan de insertar la revolución dentro de unos parámetros religiosos y fácilmente comprensibles a la luz del Evangelio. Ya es sintomático que el sermón viniera encabezado por una cita en latín del Eclesiástico, 45.4: "sanctus fecit illum, et eligit eum ex omni carne" (le santificó, le eligió entre toda carne). La referencia bíblica a Moisés se trasmuta de inmediato en boca de Carrascón en la del caudillo José Angulo, el elegido como cabeza de la insurgencia. El paralelismo entre la cita empleada y el hecho político resulta evidente y el clérigo se recrea en ello de este modo:

26 Ambos se encuentran en AGI, Cuzco, 71. Uno y otro son extractados en ApAricio VEGA, 1974, pp. 116-121, el primero; pp. 114-115, el segundo. También en este caso trabajamos con el original manuscrito.

27 Véase Herrejon Peredo, 2000.

28 Sobre el impacto de estos "papeles", consúltese GLAVE, 2003.

29 Para un acercamiento a la vida y obra del Lunarejo, véase TAMAYO VARGAS, 1982, pp. IX-LVIII. 
Por estas palabras en las que el Eclesiástico forma un hombre santo, lo elige sin acepciones de personas y lo hace aparecer grande a la presencia de todas las gentes parece que son las propias con las que en esta feliz época el Todopoderoso establece este su imperio peruano [...], y también lo forma de la estirpe de todas las Naciones.

Tampoco ofrece duda la identificación de José Angulo como el hombre elegido para encabezar la revolución y el salvador providencial del Perú:

[...] un Angulo peruano [dice], hijo de la dominación española y peruana, el que la Divina Providencia fuit illum santum in fide et lenitate et elegit eum ex omni carne, para que todos sus pobladores, vecinos y habitantes del Perú reconociesen que es el brazo fuerte de todos constituido para la piedra angular de la libertad de esta nuestra Patria.

El recurso simbólico no queda sólo aquí. Carrascón se sirvió de otras imágenes a fin de transmitir con mayor claridad su mensaje político. Hábilmente jugó con las palabras Angulo y angular para acrecentar la figura del caudillo. Este, además de elegido y salvador, es presentado también como el referente del nuevo imperio peruano y en el que, de nuevo, la Divina Providencia juega un papel determinante. Es ésta la que

[...] le reviste y eleva sobre sus naturales fuerzas [...] y lo constituye en cabeza angular de todo el Perú, haciéndolo grande y un hombre memorable y digno de nuestros perpetuos respetos y para que todas las gentes y sus provincias que forma esta línea (que de Buenos Aires a Lima la remontan y elevan en este su centro del Cuzco) formen en él el Angulo de nuestra unión y la cabeza de nuestros deseos.

La simbiosis político-religiosa alcanza su culminación cuando, dirigiéndose a los asistentes, exclama en estos términos:

Vosotros, compatriotas míos y regenerados en el bautismo del crucificado [...] A vosotros os toca privada y públicamente en otras casas y plazas manifestar que Dios está con vosotros por medio de nuestro general aclamado y que esta nuestra causa es suya y que se hallaba escrita en sus sagradas profecías. A vosotros os toca el manifestar que este nuestro general José es nuestro macabeo peruano que sabrá defender hasta morir con nosotros los derechos de nuestra humillada patria, simbolizada en esas banderas que acabáis de recibir para con ellas penetrar, combatir y destrozar a los enemigos de nuestra patria libertad.

Pero no sólo José Angulo aparece representado de manera simbólica y en un contexto intencionadamente religioso; otro tanto ocurre con la ciudad de Cuzco. La vieja capital inca, estratégicamente situada, es presentada como la elegida por los designios divinos y llamada a desempeñar el nuevo liderazgo continental; por ello se la identifica con Israel que luchó y se liberó de sus opresores con este símil: "El escogido pueblo de Israel diariamente gemía y cantaba [...] Lo mismo parece que ha sucedido a este tu afligido pueblo peruano".

Otra referencia simbólica del sermón viene determinada precisamente por las banderas, "esas gloriosas insignias de nuestra patria". En ellas quiere representar el 
triunfo peruano sobre la tiranía peninsular, al tiempo que las considera como una manifestación de la protección divina. Su bendición solemne en la catedral cuzqueña acentúa su simbolismo y las impregna de un hondo significado político-religioso en el que Carrascón insiste una y otra vez. Así pues,

[...] por ellas el despotismo queda destruido, abierta la puerta a la justicia y quedarnos todos bajo las banderas del Crucificado y la protección de Nuestra Madre y Señora de los Angeles [...]; hoy igualmente con sonidos más halagüeños nos habemos congregado todos en este mismo sitio para celebrar nuestros patrios triunfos y las gloriosas insignias de nuestra libertad.

Todo ello sin olvidar que eran en sí mismas el símbolo que debía animar el alistamiento de los peruanos

$[\ldots]$ hasta morir por la defensa de la justicia de nuestra patria $[\ldots]$ y con ellas penetrar, combatir y destrozar a los enemigos de nuestra patria libertad.

Por lo demás, el sermón contiene reiteradas alusiones al despotismo y tiranía del gobierno peninsular, al comportamiento arbitrario de los poderes y a la inevitable salida de España de aquellos dominios en beneficio de la nueva nacionalidad. En este sentido, el sermón no aporta ideas que no estuvieran ya recogidas en otros textos contemporáneos. Sus fines propagandísticos resultan obvios, así como su afán proselitista para la atracción de nuevos partidarios. La defensa de la revolución y sus motivos alternan con acaloradas críticas al enemigo. Los argumentos políticos y jurídicos se suceden en orden a la exaltación de la patria peruana. La apología de la libertad y la igualdad de todos emergen frente al abuso y el desgobierno de las autoridades peninsulares. La oratoria de Carrascón brilla en estos pasajes para impactar en el ánimo de sus oyentes:

Oh desgraciado reino de España, ya no existes para nosotros, sino es en la dolorosa historia de tus infamias. Ellas son las que nos han separado el día de hoy de tu dominación mas que los inmensos mares de tus distancias [...] ¿Dónde está, España, aquel tu esplendor envidiado por todas las potencias del mundo por tantos siglos? Dónde tu fortaleza con la que dominabas los mares y la mayor parte del universo? ¿Dónde tu riqueza con la que tú sola enriquecías y avasallabas a las demás naciones? [...] Todo lo has perdido. Sí, tu gloria se te ha convertido en escarnio; tu fortaleza en debilidad; tu riqueza en tu propia servidumbre. Ya no tendrás las ricas naves que te iban del Perú con las que agigantaban tu orgullo entre todas las naciones; porque tus injusticias, tus injurias, tus contumelias y tus falsedades te han conducido a tu primitivo estado para que con la humanidad y con el sudor de tu rostro comas tu propio pan, y no apetezcas el ajeno tenido con la sangre de estos tus colonos americanos.

El sermón de las banderas, en fin, constituye un buen ejemplo para comprobar hasta qué punto nuestro personaje pretendía identificar el relato bíblico con lo que estaba aconteciendo en 1814 asignando, al mismo tiempo, un papel determinante a la providencia. En el centro de su interpretación Cuzco, y por extensión Perú, son 
presentados como víctimas de una tiranía parecida a la que padecieron los judíos en Egipto; como en ésta, los líderes revolucionarios eran los Moisés y los nuevos Mesías elegidos y salvadores.

El otro sermón, pronunciado en la iglesia de la Compañía, responde a los mismos planteamientos y mezcla también, de forma intencionada, el relato bíblico con los objetivos políticos de la insurrección. En esta ocasión Carrascón toma como referencia la figura del apóstol Andrés, hermano de Simón Pedro, y el pasaje evangélico "venid en pos de mí y yo os haré pescadores de hombres". Así cómo éstos al instante dejaron su trabajo y siguieron a Jesús, Carrascón quiere llamar la atención sobre la importancia de la obediencia y la disposición a dejar todo para seguir a un líder. El texto se detiene en censurar el apego a la vida material y las conductas egoístas de los hombres; se vale del martirio de San Andrés para proponer un modelo de conducta centrada en el desprendimiento material y en el sacrificio por una causa justa. A partir de ahí, el sermón discurre en un tono donde las citas de evangelistas y profetas son reinterpretadas a la luz de los hechos políticos del momento.

El amor a la patria, piensa, está por encima del amor a uno mismo y ello es razón para luchar por ella y salvarla de la tiranía española. La lucha de independencia requiere muchos sacrificios pero, a imitación del apóstol Andrés, quienes la sigan alcanzarán también la aureola de mártires. "Oigamos, hermanos míos americanos, las voces de la propia raza y no las de nuestros personales caprichos", tal es su forma de convocar a una unión que, más allá de lo particular de cada uno, aspira a la creación de una patria común ya definitivamente separada de la española, cuyos gobernantes por su comportamiento despótico no merecen obediencia. Su argumento es claro:

Díganlo las propias leyes dictadas para este país conquistado, publíquenlo la ninguna resolución de las causas y por fin el testimonio más auténtico de la tiranía que hemos sufrido en la impunidad de los delitos más atroces de los magistrados. Esta impunidad es la que destruyendo todo el orden social de las cosas hace a los hombres enemigos de Dios y de sus semejantes y de sus Patrias. Estas constantes verdades son las que nos han separado ya de lo inhumano y sedectivo gobierno europeo más que la distancia de sus seis mil leguas.

¿Cómo y de qué forma Francisco Carrascón articuló todo este pensamiento? A falta de documentación precisa sobre esta cuestión, es posible dejar constancia de algunos hechos. Por un lado, debe repararse en su espíritu inquieto, abierto a cualquier idea y siempre bien informado. Su trayectoria y comportamiento desde que llegara a Cuzco revela que fue un hombre con un decidido afán de protagonismo, muy interesado en su promoción personal y resuelto a no desfallecer ante la adversidad. Preocupado por aparecer como un vasallo fiel e interesado por el bienestar del país, de ser un cristiano celoso de su trabajo y de sus obligaciones, chocó frontalmente con aquellas autoridades de las que pensaba que sólo recibía el desprecio y la condena. Sin duda esta circunstancia le atormentó y podría explicar la visión tan negativa que tuvo de los funcionarios reales y que tantas veces reflejó en sus cartas y memoriales. Ese mismo ánimo está presente tanto en la proclama como en los sermones donde no pierde la ocasión, una vez más, de airear las injusticias de que ha sido objeto durante su estancia en Cuzco. Por tanto, cabría plantear la posibilidad de que su paso a la 
insurgencia fuera un acto de venganza por los agravios recibidos. Algunos pasajes de esos textos evidencian que, en efecto, la nueva situación le brindó el escenario adecuado para descargar sus resentimientos y arremeter contra un sistema que pensaba le había postergado injustamente. Desde tal perspectiva, su actitud puede considerarse más bien como una crítica al mal gobierno antes que una inquietud separatista, aunque fuera ésta última la que expresara con mayor rotundidad.

Por otro lado, debe tenerse en cuenta su amplia formación intelectual que resultó ser decisiva para cimentar y defender su discurso ideológico. Sobre ello dice mucho el contenido de su biblioteca personal ${ }^{30}$. En ella figuraban, junto a títulos propiamente religiosos, libros de naturaleza política, textos jurídicos, de historia, filosofía, teología y moral. No se encontraban libros prohibidos, aunque hubo algún compañero de la catedral que lo acusase de leer a "Voltaire, Rousseau y otros herejes" 31. Sí disponía, en cambio, de un Índice de libros prohibidos. Su defensa a ultranza de las regalías del monarca frente a la autoridad de la Iglesia hizo de Carrascón un sacerdote combativo, enfrentado a su propio obispo por un conflicto de jurisdicciones. Los textos de Bossuet y de Ribadeneira, también presentes en su biblioteca, sin duda le sirvieron para afianzar sus ideas en este campo. La presencia de las obras de Francisco Suárez y del Padre Mariana avala su conocimiento de las tesis populistas. Tampoco faltaban textos de Cicerón, Aristóteles y Solórzano Pereira. La España Sagrada del padre Florez compartía estante con la vida de San Francisco de Borja, las cartas de Santa Teresa y textos de Saavedra Fajardo o Feijoo. Una biblioteca, en su suma, que da una imagen certera de su dueño y de su formación intelectual y que merece un estudio más detenido.

Así pues, la agitada biografía de Carrascón desde su llegada a Cuzco, la polémica de su comportamiento y la reprobación tanto de las autoridades políticas como religiosas, junto a su abierta formación intelectual, podrían considerarse como elementos clave para explicar cómo este zaragozano terminó involucrado en la revolución. Caso singular, por otro lado, ya que ilustra sobre el compromiso independentista de un sacerdote peninsular junto a sus compañeros criollos o mestizos.

\section{EL PROCESO Y LA SENTENCIA}

Todos los anhelos separatistas de Francisco Carrascón quedaron frustrados con el triunfo de la causa realista. A la ejecución de los líderes principales de la revolución siguieron los juicios contra el resto de los implicados. Para instruir el proceso contra Carrascón fue comisionado el juez Pedro López de Segovia. No deja de ser curioso que se multiplicasen las dificultades para nombrar tanto al fiscal como al abogado defensor. El fiscal inicialmente propuesto, Pedro Manuel de Urbina, declinó el nombramiento alegando que Carrascón era "el único enemigo capital que conozco en el discurso de mi vida" y que en fechas recientes ya se había enfrentado con él a propósito de la defensa que tuvo que hacer del regente y fiscal de la

30 El contenido de la misma se conoce a partir del embargo de sus bienes ordenado por las autoridades militares en 1815 con motivo de la causa militar que se le siguió. La relación de libros que la componían se halla en AGI, Cuzco, 71. Fue publicada en ColECCIÓn, 1974, T. II, vol. 7, pp. 539-546.

31 Denuncia del presbítero Mateo Guillen. Cuzco, 15-XII-1803. AGI, Cuzco, 73. 
Audiencia. "Esta consideración no solo me exime en lo legal, sino que pone trabas a mi conciencia para obrar con la pureza correspondiente en asunto de tanta gravedad"32. Aceptada la renuncia, el nombramiento de fiscal recayó en Francisco de Paula Sotomayor Galdós, también abogado de la Real Audiencia. Más problemas tuvo Carrascón para encontrar a la persona que se ocupara de su defensa. Sucesivamente fueron propuestos los abogados Manuel Galeano, Luis de Astete, Ignacio Mariano Maldonado, Miguel Vargas y José Mariano de Ugarte. Con diferentes argumentos ninguno aceptó el nombramiento y fue necesaria una orden expresa de Juan Ramírez, general en jefe de los ejércitos de Cuzco, para obligar a Ugarte, que entonces ejercía como alcalde de primer voto, a que asumiera la defensa.

Fiscal y defensor trabajaron a la vista de la declaración que Carrascón hizo sobre los hechos que se le imputaban y en la que ofreció una interpretación tan novedosa como sorprendente de su comportamiento ${ }^{33}$. En realidad no podía esperarse otra cosa de un personaje que había dado ya sobradas muestras de una gran habilidad para saltar de acusado a víctima inocente. En esta ocasión defendió y justificó sus actos con dos argumentos: a) actuó forzado por los insurgentes; y b) cuanto hizo fue por amor a los hombres y para salvar la vida de los españoles presos por José Angulo. Así pues, su alegato se centró en demostrar que su participación en la insurgencia, además de obligada por las circunstancias, estuvo motivada por fines piadosos. Por tanto, concluyó que su actitud era digna de recompensa y nunca merecedora de calificarse como criminal.

Durante dos días de interrogatorio pudo exponer tales argumentos y sortear las preguntas del juez. A la cuestión de porqué un sacerdote oriundo de España se implicó en la revolución y trabó amistad con sus líderes, respondió

[...] que jamás ha alternado directa ni indirectamente, ni menos con su voluntad, con los caudillos insurgentes y que si lo ha hecho ha sido por libertar la vida de los presos europeos y la suya.

Preguntado sobre las expresiones contra el rey y sus críticas al gobierno español con incitación a la independencia, replicó que sus palabras se malinterpretaron porque sus verdaderos objetivos eran humanitarios; lo que escribió era un "sagaz medio" para que el virrey tuviera noticia del "infeliz estado en que estaban los europeos", y pudiera adoptar

[...] las mas oportunas y prontas providencias para la deseada libertad, entretanto el suplicante los iba entreteniendo así con la mencionada proclama, como también con otras cosas que ideaba del mismo efecto.

Restó importancia a las frases más comprometedoras de sus escritos y subrayó que no eran más que simples expresiones copiadas de las muchas similares que circulaban por la ciudad y que jamás fue su intención atentar contra la soberanía.

32 Oficio de Pedro Manuel de Urbina a Juan Ramírez. Cuzco, 19-IV-1815. Cuzco, 71.

33 Declaración de Francisco Carrascón. Cuzco, 15-IV-1815. Ibídem. Las citas que siguen han sido extraídas de la misma. 
En última instancia, llegó a confesar que las palabras que se le atribuían le habían sido impuestas por los insurgentes y que "no pudieron ser dictadas por su razón, aunque sí escritas por la fuerza". Interpelado una vez más por qué sus sermones llamaban a la separación e insistían en calificar al gobierno español de injusto y tiránico, reiteró que fue forzado por los insurgentes, quienes le obligaron a que predicara en tal sentido. Por otro lado, sostuvo que acordó escribir los sermones para que no se atentara contra la vida de los europeos a quienes, decía, se les amenazaba diariamente y se les hacia confesar para eludir el castigo. De lo cual dijo sentirse muy satisfecho porque gracias a su decisión los prisioneros habían logrado mejorar su estado, un éxito que no alcanzó el regente de la Audiencia con sus negociaciones ante los líderes de la revolución. La idea de salvar a los españoles presos y a sí mismo era recurrente y, en su opinión, la más prudente en aquellas difíciles circunstancias puesto que

[...] el no saber nada en tantos años de nuestro amado rey Fernando y así antes bien decirse de publico y notorio que era ya muerto con toda su real familia y que los franceses dominaban la España con el nuevo rey José Bonaparte nos hizo a todos conocer que con nuestra muerte nada remediábamos para que los debidos fueros del soberano fuesen respetados en este País tumultuoso.

¿No existían otros medios para proteger a los españoles antes que la redacción de proclamas ofensivas al rey e instigadoras de la sedición? Por la respuesta a esta pregunta sabemos que Carrascón intercedió con frecuencia ante José Angulo para que los presos no sufriesen daño y que sus frecuentes reuniones con el líder obedecían a tan loable fin y no a una estrategia conspiradora.

Por el contrario, los testigos que comparecieron en la causa coincidieron en situar a Carrascón en el bando revolucionario, atribuyéndole un destacado protagonismo en aquellos hechos y resaltando la amistad y ascendencia que le unía a José Angulo. Todos convinieron en el carácter radical, denigratorio y sedicioso vertido en su proclama y sus sermones. Entre estos testigos sobresale Catalina Segarra, esposa del militar José Domingo de Errasquín. Declaró ésta haberse sentido violentada por Carrascón al increparle que debía morir junto a toda su familia y demás señoras cuyos maridos estaban en el ejército del rey en Arequipa; que la obligó a escribir una carta a su esposo para que abandonara filas si no quería sufrir mayores vejaciones. Finalmente puso en boca del sacerdote las siguientes palabras:

[...] nosotros no pretendemos otra cosa que ser libres, y que aunque se coronase un carnicero, un zapatero o un tocuyero, nada era, porque el rey de España no tenia nada aquí y que aunque saliese Lucifer mismo del infierno y se coronase, sería mejor su gobierno que el del rey de España ${ }^{34}$.

La parte fiscal centró su informe en poner de manifiesto la conducta reprobable del acusado sobre la base de lo escrito en la proclama y en los dos sermones. Presentó a Carrascón como

34 Declaración de Catalina Segarra. Cuzco, 10-IV-1815. AGI, Cuzco, 71. Durante el careo mantenido Carrascón negó aquellas acusaciones, pero la testigo permaneció firme en su declaración. 
[...] un eclesiástico formando proclamas y sermones y aun predicándolos, incitando los ánimos a la rebelión, justificándola por debida, justa y necesaria en el derecho de los humanos [...]; un desconcertado proyectista que organiza planes para realizar la unidad proyectada por los porteños [...], que traza el modelo de formar una nación libre e independiente en el globo americano [...]; un desenfrenado e implacable declamador contra la monarquía española, denominando su gobierno injusto, venal y engañador [...]; el más insolente blasfemador contra las augustas regalías de nuestro católicos monarcas $[\ldots]$; un temerario censurador de las operaciones de ministros [...]; el más exacto obediente de los intereses del infame Angulo, su mejor director, el panegirista de sus detestables acciones, el consultor en sus dudas, el ejecutor de sus deliberaciones [...]; un profanador de la cátedra del Espíritu Santo, que vierte desde allí las expresiones más seductivas, erróneas, mal sonantes, ofensivas de piadosos oídos ${ }^{35}$.

Por otro lado, se hizo eco de los planteamientos manifestados por Carrascón en su favor, aunque no los consideraba eximentes de culpa sino una estrategia para la defensa. Desde este punto de vista, presentó una imagen del sacerdote notablemente diferente de la anterior. Ahora lo veía como

[...] un europeo que viendo presos a sus paisanos y aun sentenciados a muerte vivía anonadado, humillado y sobresaltado, reputado sospechoso contra el sistema de la insurrección [...]; un hombre oprimido por las lastimosas catástrofes que observaba y precisado por estas razones a elegir la muerte o a abrazar siquiera externamente la infidencia [...]; un verdadero ministro del Dios de la Paz que ejecuta aun lo que no le es permitido por impedir las guerras civiles y el torrente de la sangre de sus hermanos, especialmente de los europeos y señores magistrados que se hallaban presos.

Un perfil que el fiscal se apresuró a decir que era negado por los hechos y que no debía de ocultar las verdaderas intenciones del acusado, las cuales aparecían bien explícitas a lo largo de su proclama y de sus sermones. Pese a ello, la conclusión fiscal puede considerarse bastante moderada, ya que se limitó a proponer que el acusado fuera enviado a España para que en la Corte se le siguiera la causa y ello con conocimiento de la superioridad eclesiástica ${ }^{36}$. Fundó su dictamen en leyes que impedían que ningún juez local pudiera entender en causas donde se discutía la soberanía del monarca. En ningún momento pidió para él la pena de muerte.

La defensa, por su parte, dirigió sus miras a lograr que Carrascón fuera reconocido como

35 Informe del promotor fiscal, Francisco de Paula Sotomayor Galdós. Cuzco, 22-IV-1815. AGI, Cuzco, 71.

36 "Se remita al prebendado Francisco Carrascón bajo de buena guardia y custodia ante la presencia real juntamente con la presente causa... y que sus bienes se apliquen a la cámara de su majestad, ejecutándose todo con intervención, acuerdo y conocimiento de su Ilustrísimo Prelado en cumplimiento de las leyes que imponen estas penas a los clérigos que se atreven a proferir contra la sagrada persona del rey las palabras y expresiones que ha osado verter dicho Carrascón, como también contra sus augustas regalías, contra sus justificados ministros y contra el gobierno legitimo y, en obsecuencia, de las que tratan acerca de los eclesiásticos que se mezclan en motines y tumultos". Informe del promotor fiscal, Francisco de Paula Sotomayor Galdós. Cuzco, 22-IV-1815. AGI, Cuzco, 71. 
[...] un hombre poseído de sentimientos de fidelidad a nuestro dignamente amado soberano el señor don Fernando VII [y probar] el espíritu de humanidad, caridad y lenidad sacerdotal que le indujo por falta de otro medio a asegurar las vidas de los respetables magistrados y los europeos que fueron presos e incisamente eran amenazados con la muerte ${ }^{37}$.

En un largo escrito rebatió los argumentos del fiscal e hizo suya la estrategia planteada por el acusado; por ello insistió en el hecho de que su defendido se sintió amenazado como europeo por los insurgentes y que, temeroso de ser ejecutado como otros, no tuvo más remedio que abrazar externamente las ideas de aquéllos:

Formó el proyecto de fingirse patriota y obrar contra sus propios sentimientos usando de una máxima política que le pareció necesaria y aún única adoptable a aquellas circunstancias.

Con semejante astucia, argumentaba el abogado, no sólo salvó su vida, sino que pudo trabajar para la defensa de los otros presos. José Mariano de Ugarte dio fe de la eficacia de este plan recordando que él mismo había eludido la prisión el 18 de marzo de 1815 gracias a la gestión de Carrascón ante los insurrectos. Aunque discutible, reconocía que fue la mejor opción que pudo adoptar y recordaba que por menos motivos otros eclesiásticos habían sido ejecutados ${ }^{38}$.

Aunque consideraba la proclama como "un papel más digno del fuego que de ser leído", llamó la atención sobre el hecho de que el verdadero espíritu de aquel texto era muy distinto del que se le atribuía. Más allá de la literalidad de sus expresiones, la proclama no pretendía otra cosa que frustrar el proyecto de Angulo y alertar al virrey de la gravedad de lo que acontecía en Cuzco para que tomara medidas. En cuanto a los sermones, volvió a insistir en que su defendido fue forzado a su redacción y que consintió en ello por las amenazadas recibidas.

Por tanto, las conclusiones de la defensa sostenían que Carrascón

[...] no ha sido delincuente ni abrazó el perverso y perjudicial sistema de la patria, ni era posible que lo abrazase porque aquel no anunciaba sino un total exterminio no solo de los europeos, sino aún de todo hombre blanco".

Solicitó su absolución para que quedara libre del crimen que se le imputaba y se le tuviera como "un fiel servidor del rey y un ciudadano lleno de sentimientos de humanidad y religión". Del mismo modo reclamó la devolución de todos los bienes embargados.

A la vista del informe fiscal y del alegato de la defensa, una comisión de guerra, presidida por el coronel comandante Juan de Dios Paraina, e integrada por el coronel comandante Julián de la Llave y los tenientes coroneles Manuel Venero, Agustín Gamarra y Mariano Gómez, dictó sentencia contra Francisco Carrascón el 17 de

37 Alegato de la defensa por José Mariano de Ugarte. Cuzco, 30-IV-1815. AGI, Cuzco, 71.

38 Traía a colación el caso de Mariano Alegría, muerto por no haber recibido bajo palio a Pumacahua y el del padre fray Juan Jesús, viceprefecto de la Almudena, por no haber vitoreado "Viva la Patria". 
mayo de 1815, condenándolo a pena ordinaria de muerte. Se le acusó de complicidad en la insurrección y declamador público de la misma, llamándola "santa, universal, gloriosa y perpetua"; de estar al servicio de los Angulo; de incitar a la población para la consecución de un proyecto "de nación libre e independiente"; de haber ultrajado el nombre de Fernando VII y criticado la dominación española; en fin, de ser autor de diferentes escritos cuyo contenido no era otro que llamar a la insurgencia y poner fin al estado monárquico español ${ }^{39}$.

Lejos de ejecutarse dicha sentencia en Cuzco, Juan Ramírez determinó que el prisionero fuera enviado a Lima con otros encausados, entre ellos el cura de Lares, Juan Angulo, para que quedara a disposición del virrey y éste decidiera lo más conveniente al caso. Abascal y Sousa pidió el acuerdo de la Real Audiencia sobre el particular y ésta acordó que los reos fueran conducidos a la península para que el rey tomara la última decisión ${ }^{40}$. Así se hizo y Carrascón embarcó en Lima a bordo de la nave Alcides con rumbo a Cádiz, hallándose ya confinado en el castillo de San Sebastián a principios de marzo de $1816^{41}$.

Hasta 1817 permaneció en prisión y durante todo ese tiempo siguió elevando escritos al rey, proclamando su inocencia y denunciando ser víctima de una persecución injusta que se prolongaba ya durante casi dos décadas. En uno de ellos pedía audiencia para poder defenderse "de la multitud de nulidades con las que se le ha procesado", se presentaba como "víctima de la insurgencia" y perseguido y pobre a causa de su patriotismo y afecto al rey ${ }^{42}$. Solicitó acogerse al indulto proclamado por Fernando VII para eludir la pena de muerte ${ }^{43}$, el cual le fue concedido por decisión del Consejo que, además, observó ciertas anomalías en el proceso que se le siguió en $\mathrm{Cuzco}^{44}$. Fue puesto en libertad con prevención de no volver a América y ser vigilada su conducta. Misión ésta que se encomendó al obispo de Córdoba, hasta donde marchó Carrascón en espera de obtener algún cargo. Aquí lo único que se le ofreció fue el economato del pueblo de San Nicolás de la Villa de Córdoba ${ }^{45}$; un destino que consideró muy inferior a sus pretensiones y por ello no tuvo escrúpulos en sugerir al monarca otros destinos más adecuados a su trayectoria. Por ejemplo, alguno de los tres puestos que desempeñaba el presbítero Angel de los Arcos (canónigo en Córdoba, administrador general y capellán mayor del Hospital de la Pasión en la Corte y capellán de honor del rey) ${ }^{46}$; en su defecto, una canonjía vacante en la cate-

39 Sentencia contra Francisco Carrascón. Cuzco, 17-V-1815. AGI, Cuzco, 71.

40 Carta del virrey Abascal al Secretario de Estado. Lima, 26-VIII-1815. AGI, Cuzco, 71.

41 Carta del presidente juez de arribadas, Rafael Orozco, al ministro de Gracia y Justicia. Cádiz, 5III-1816. AGI, Cuzco, 71.

42 Carta de Francisco Carrascón al rey. Madrid, 20-VI-1817. AGI, Cuzco, 73.

43 El documento está fechado en Madrid el 24 de enero de 1817. Carrascón se acogió a su punto $4^{\circ}$, según el cual el perdón se hacía "extensivo a los reos procesados y no procesados, presentes o ausentes, procesados por delitos de insurrección cometidos antes de la publicación de este indulto".

44 El Consejo precisó que "fue juzgado por un juez ajeno al fuero eclesiástico, sin intervención de su prelado y sentenciado sin citación y audiencia del acusado, sino por un breve sumario militar incompleto". Dictamen del Consejo de Indias. Madrid, 12-IX-1817. AGI, Cuzco, 73.

45 Carta del obispo de Córdoba al Consejo de Indias. Córdoba, 18-III-1820. AGI, Cuzco, 73.

46 Representación de Francisco Carrascón al rey. Madrid, 28-VI-1820. AGI, Cuzco, 73. 
dral de Guadalajara (México) ${ }^{47}$ y, finalmente, la incorporación al Estado Mayor de capellanes propietarios del ejército en Madrid ${ }^{48}$.

Evidentemente no obtuvo respuesta satisfactoria a tan exigentes demandas. La última noticia, antes de perderse su rastro, data de 1827 cuando solicitaba en su Zaragoza natal un cargo en aquel arzobispado. No había perdido a sus 69 años un ápice de su espíritu reivindicativo, combativo, infatigable y ajeno a toda desesperanza. Su trayectoria vital resulta tan sorprendente como apasionada, propia de un hombre que vivió con intensidad cuantos problemas y dificultades buscó o halló en su camino. Demostró su arrojo y osadía enfrentándose en Cuzco a Bartolomé de las Heras, su arzobispo, y tomó la arriesgada decisión de abrazar la causa de los insurgentes en 1814 en la defensa de unos ideales.

\section{REFERENCIAS BIBLIOGRAFICAS}

AGUIRRE, Rodolfo - ENRÍQUEZ, Lucrecia

2008 La Iglesia hispanoamericana, de la colonia a la república. México. Universidad Nacional Autónoma de México - Pontificia Universidad Católica de Chile.

AnNIno, Antonio - GuERRA, François-Xavier (coords.)

2003 Inventando la nación. Iberoamérica siglo XIX. México. Fondo de Cultura Económica.

Aparicio Vega, Manuel Jesús

1974 El clero patriota en la rebelión de 1814. Cuzco.

BARRAgán, Rossana - CAJIAS, Dora - QAYUM, Seemin (comps.)

1997 El siglo XIX. Bolivia y América Latina. La Paz. Muela del Diablo Editores.

BERRUEZo LEÓN, $M^{\mathrm{a}}$ Teresa

1986 "Los ultraconservadores americanos en las Cortes de Cádiz (18101814)". Revista de Indias. Madrid. vol. XLVI. n 177, pp. 169-198.

COLECCIÓN

1974 Colección Documental de la Independencia de Perú. Lima. Comisión

CAHILl, David Nacional del Sesquicentenario de la Independencia del Perú.

1984 "Curas and social conflicto in the doctrinas of Cuzco. 1780-1814". Journal of Latin American Studies. Londres. vol. 16. n 2, pp. 241-276. http://dx.doi.org/10.1017/S0022216X00007070

DEMELAS, Marie-Danielle

1995 "La guerra religiosa como modelo". En GUERRA (coord.), pp. 143-164.

1997 "Las insurrecciones andinas, 1809-1825: la guerra religiosa como modelo". En BARRAGÁn - CAJÍAS - QAYUM (comps.), pp. 79-95. 2003 "Estado y actores colectivos en los Andes". En ANNINO GuERRA (coords.), pp. 347-377.

47 Representación de Francisco Carrascón al rey. Madrid, 4-XII-1820. AGI, Cuzco, 73.

48 Representación de Francisco Carrascón al rey. Madrid, 20-IX-1821. AGI, Cuzco, 73. 
FISHER, John

1979 "Royalism, regionalism and rebellion in colonial Peru, 1808-1815". Hispanic American Historical Review. Durham. vol. 59. no 2, pp. 232-257.

GARCÍA JordÁn, Pilar

1982 "Notas sobre la participación del clero en la independencia del Perú: aportación documental". Boletín Americanista. Barcelona. no 32, pp. 139-147.

GARCÍA JoRDÁn, Pilar - IZARD, Miquel, (coords.)

1991 Conquista y resistencia en la Historia de América. Barcelona. Universidad de Barcelona.

GLAVE, Luis Miguel

2001 "Antecedentes y naturaleza de la revolución de Cuzco y el primer proceso electoral". En O'PHELAN GODOY (comp.), pp. 77-97.

2003 "Una perspectiva histórico cultural de la revolución del Cuzco en 1814". Revista de las Américas. Historia y presente. Valencia. no 1, pp. 11-38.

2004 La república instalada. Formación nacional y prensa en el Cuzco, 1825-1839. Lima. Instituto de Estudios Peruanos.

2005a "La ilustración y el pueblo: el "loco" Bernardino Tapia. Cambio y hegemonía cultural en los Andes al fin de la colonia. Azángaro 1818". Tiempos de América. Castellón. no 12, pp. 133-150.

2005b "Las otras rebeliones: cultura popular e independencias". Anuario de Estudios Americanos. Sevilla. vol. 6. nº 1, pp. 275-312.

GuERrA, François-Xavier (coord.)

1995 Las revoluciones hispánicas: independencias americanas y liberalismo español. Madrid. Editorial Complutense.

Herrejón PEREDo, Carlos

2000 "El sermón barroco en el mundo hispánico: estudio de dos latitudes". En Mazin Gómez, Oscar (ed.). México en el mundo hispánico. T. 1. Zamora. El Colegio de Michoacan, pp. 343-362.

KAIBLER, Jeffrey S.J.

2001 El clero y la independencia del Perú. En O'PHELAn Godoy (comp.), pp. 119-135.

LANDAVAZO, Marco Antonio

2001 La máscara de Fernando VII. Discurso e imaginario monárquicos en una época de crisis. Nueva España, 1808-1822. México. El Colegio de México - Universidad Michoacana de San Nicolás Hidalgo - El Colegio de Michoacán.

Molina MartíneZ, Miguel

2008 “Tensiones eclesiásticas en Cuzco. El caso de Francisco Carrascón”. En AGUIRRE - ENRÍQUEZ (coords.), pp. 259-275.

O'Phelan Godoy, Scarlett

1985 "El mito de la independencia concedida: los programas políticos del siglo XVIII y del temprano XIX en el Perú y Alto Perú (1730-1814)". Histórica. Lima. vol. IX. no 2, pp. 155-191. 
O'Phelan Godoy, Scarlett (comp.)

2001 La independencia del Perú. De los Borbones a Bolivar. Lima. Pontificia Universidad Católica del Perú-Instituto Riva-Agüero.

Peralta Ruiz, Victor

1996 "Elecciones, constitucionalismo y revolución en el Cuzco,

1809-1815”. Revista de Indias. Madrid. vol. LVI. no 206, pp. 99-131.

http://dx.doi.org/10.3989/revindias.1996.i206.819

RAMOS, Gabriela (comp.)

1994 La venida del reino. Religión, evangelización y cultura en América, siglos XVI-XX. Cuzco. Centro Bartolomé de las Casas.

ROMERo, José Luis - ROMERO, Luis Alberto

1977 Pensamiento político de la emancipación. Caracas. Biblioteca Ayacucho.

SALA I VILA, Nuria

1991 "La participación indígena en la rebelión de los Angulo y Pumacahua, 1814-1816”. En GARCíA JORDÁN - IZARD (coords.), pp. 273-288.

1994 "Algunas reflexiones sobre el papel jugado por la iglesia y el bajo clero en las parroquias de indios en Perú (1784-1812)". En Ramos (comp.), pp. 339-362.

$1996 Y$ Y se armó el tole tole: tributo indígena y movimientos sociales en el Virreinato del Perú, 1784-1814. Ayacucho. Instituto de Estudios Regionales José María Arguedas.

TAMayo VArgas, Augusto

1982 Apologético de Juan de Espinosa Medrano. Caracas. Biblioteca Ayacucho.

VARETTO, Juan C.

1922 Hostilidad del clero a la independencia americana. Buenos Aires. Imprenta Metodista.

VARGAS UGARTE, Rubén

1945 El episcopado en tiempos de la emancipación sudamericana. Buenos Aires. Editorial Huarpes. 